\title{
Elements Diffusion of the Interface for Be/ 00Cr17Ni14Mo2 Stainless Steel with Cu Interlayer by Vacuum Diffusion Bonding
}

\author{
Hui Li $i^{a}$, Yingkun Gong, Yilin Chen, Fei Duan and Xuan Wang
}

Chongqing Academy of Metrology and Quality Inspection, Chongqing 401123, China

aLihui@cqu.edu.cn, ${ }^{\text {b1 } 13667669535 @ 163 . c o m ~}$

*Corresponding author, Lihui@cqu.edu.cn

Keywords: beryllium, 00Cr17Ni14Mo2 stainless steel, copper, diffusion bonding, element diffusion, interface.

\begin{abstract}
Diffusion bonding is an effective way to join beryllium with other materials. To study the elements diffusion on the bonding interface to improve the joints performance, the microstructure, and the distribution of composition and phase on the interface of $\mathrm{Be} / \mathrm{Cu} / 00 \mathrm{Cr} 17 \mathrm{Ni} 14 \mathrm{Mo} 2$ stainless steel diffusion bonding were analyzed using scanning electron microscopy (SEM), energy dispersive spectrometer (EDS), scanning auger microscopy (SAM), x-ray diffraction (XRD), and the elements diffusion on the interface and the relationship between phases distribution and microstructure were also discussed. The result show that the original interface of $\mathrm{Be} / \mathrm{Cu}$ diffusion bonding is the most weak site of the whole diffusion bonding zone and the fracture site of specimen. Dissimilar metal atoms gather first in the grain boundary and form intermetallic compounds, and the grain boundary or intermetallic compounds are the main gateway of the elements diffusion. The copper interlayer has greatly hindered the interdiffusion between stainless steel elements and beryllium, so the formation of intermetallic compounds between beryllium and stainless steel elements are avoided effectively to improve the diffusion bonding joints strength.
\end{abstract}

\section{Introduction}

In these years, scholars carried on a lot of research on diffusion bonding of dissimilar metals, which focused mainly on diffusion bonding of dissimilar metals with[1-5] and without[6-8] an interlayer material. Beryllium is a reactor material, because it has the lowest $Z$, relatively high thermal conductivity, low activation, etc. Diffusion bonding is an effective way to join beryllium with other materials. With the process, joining of materials is achieved through atomic transport and mechanical processes at the bonding interface. It is difficult to bond beryllium with 00Cr17Ni14Mo2 stainless steel, because beryllium is very brittle, and beryllium with the main elements of $00 \mathrm{Cr} 17 \mathrm{Ni} 14 \mathrm{Mo} 2$ stainless steel easily form brittle intermetallic compounds in the process of diffusion bonding. Therefore, copper interlayer between beryllium and 00Cr17Ni14Mo2 stainless steel is used to reduce the mutual diffusion between beryllium and stainless steel eliments, and the formation of brittle intermetallic compounds. In this paper, the elements diffusion on the interface of $\mathrm{Be} / \mathrm{Cu} / 00 \mathrm{Cr} 17 \mathrm{Ni} 14 \mathrm{Mo} 2$ stainless steel diffusion bonding in terms of the microstructure and the distribution of elements and phases have been investigated, and good joint can be obtained using copper as an interlayer material.

\section{Experimental Procedure}

\section{Materials and Specimens}

Beryllium specimens are made of hot-pressed beryllium, which composition show in Table 1 . The 00Cr17Ni14Mo2 stainless steel (SS) is the austenite anti- hydrogen stainless steel and the impurity total contents is less than $0.17 \%$, which the main alloying elements content show in Table 2 . Bars of Beryllium and SS are $10 \mathrm{~mm}$ in diameter and $5 \mathrm{~mm}$ in height. Diffusion bonding was achieved by 
hot pressing at $50 \mathrm{MPa}$ and $750^{\circ} \mathrm{C}$ in $10^{-3} \mathrm{~Pa}$ vacuum, and the holding time is $2 \mathrm{~h}\left(750^{\circ} \mathrm{C} / 50 \mathrm{MPa} / 2 \mathrm{~h}\right)$. copper foil of $50 \mu \mathrm{m}$ in thickness is used as interlayers 。

Table1. The content of heat pressed Be powder, w/\%

\begin{tabular}{ccccccccc}
\hline Be & $\mathrm{Fe}$ & $\mathrm{Al}$ & $\mathrm{Ni}$ & $\mathrm{Cr}$ & $\mathrm{Mn}$ & $\mathrm{Pb}$ & $\mathrm{Mg}$ & $\mathrm{O}$ \\
\hline Bal. & 0.18 & 0.078 & 0.003 & 0.01 & 0.013 & 0.001 & 0.12 & 0.75 \\
\hline
\end{tabular}

Table2. The content of SS, w/\%

\begin{tabular}{ccccc}
\hline $\mathrm{Fe}$ & $\mathrm{Cr}$ & $\mathrm{Ni}$ & $\mathrm{Mo}$ & $\mathrm{Mn}$ \\
\hline Bal. & 17.2 & 14.27 & 2.19 & 1.05 \\
\hline
\end{tabular}

\section{Instruments and Experiment Method}

The microstructure morphologies were recorded using TESCAN VEGA3 SBH scanning electron microscopy (SEM). The composition of the diffusion bonding zone were recorded using BRUKER QUANTAX 100 energy dispersive spectrometer (EDS). The XRD pattern were recorded using D/MAX-1200 X-ray diffraction, at a Cu-anode, $40 \mathrm{kV}$ tube voltage, $30 \mathrm{~mA}$ tube current and $2^{\circ}$ $\mathrm{min}^{-1}$ scanning speed. The SAM spectra were recorded using PHI650SAM scanning auger microscopy, at $3 \mathrm{kV}$ electron excitation energy, $0.25 \%$ energy resolution, $100 \mathrm{nA}$ electron beam current. A tensile tester was used for testing the mechanical properties of the joints.

\section{Results and Discussion}

\section{Experimental}
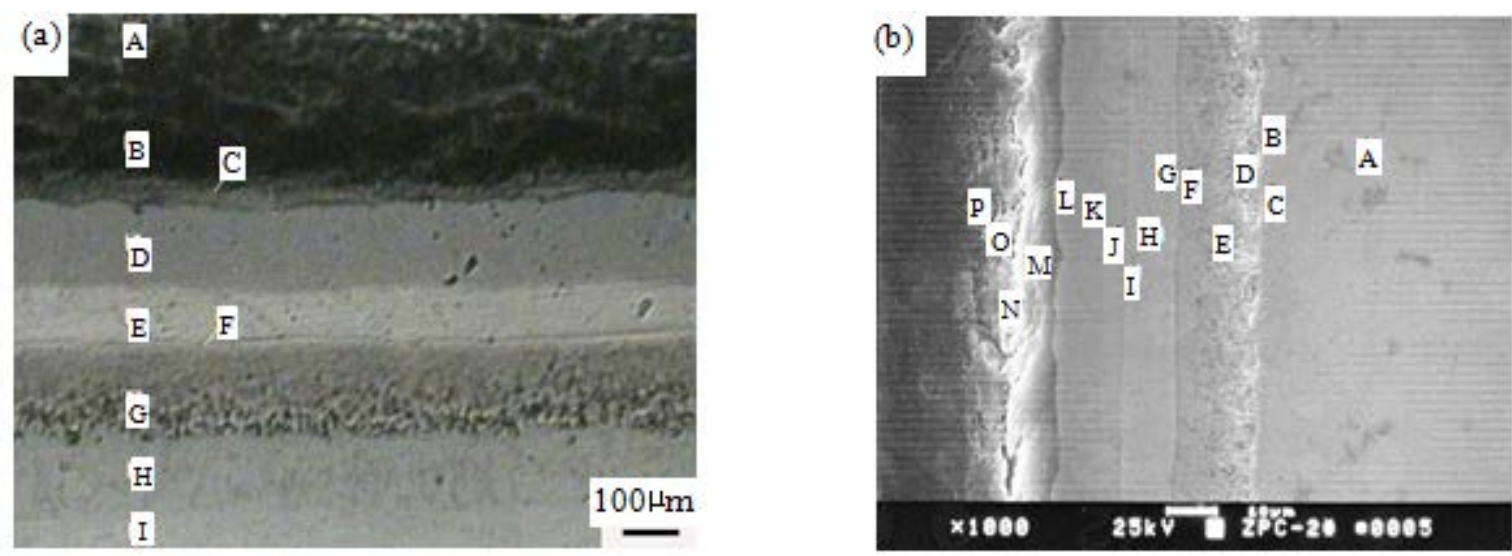

Fig.1 The microstructure of joint zone. (a) Metallurgical micrograph, (b) SEM micrograph.

The microstructure of $\mathrm{Be} / \mathrm{Cu} / 00 \mathrm{Cr} 17 \mathrm{Ni} 14 \mathrm{Mo} 2$ stainless steel diffusion bonding joint show in Fig. 1. Fig. 1 (a) shows that the diffusion bonding zone includes A, B, C, D, E, F, G, H and I layer, which are almost parallel and perpendicular to the outside forces direction. The results of EDS testing each zone in Fig.1 (b) show in Table 3, which the contents of chromium, copper, molybdenum and nickel are about 19\%, 10\%, 4\% and 2\% in the DEF layer (SS side), respectively, and some phases are corroded to pit by aqueous nitric acid. There are about $87 \%$ copper and $9 \%$ nickel in the GHI layer, which shows good corrosion resistance. Becauase copper and nickel are face centered cubic lattice and the lattice constants are similar, they can form the infinite displacement solid solution for corrosion resistance. The copper content is increased (average 93\%) and the nickel content is reduced in the JKL layer, which also shows excellent corrosion resistance. Because the energy dispersive spectrometer (EDS) can not detect beryllium, the main element is copper in the MNOP layer (beryllium side), and it is reason that the elements content are the relative in the beryllium side. 
Therefore, Fig. 1 b shows that A part is the SS matrix, EF layer and BCD layer are respectively diffusion zone and diffusion transition zone in the SS side, GHIJKL layer is the intermediate bonding region (the original copper interlayer), MNO layer is the diffusion bonding zone between the original copper interlayer and beryllium, $\mathrm{P}$ part is diffusion zone in the beryllium side, The D/C interface is the boundary between the diffusion transition zone and the SS matrix in the SS side, The $\mathrm{G} / \mathrm{F}$ interface is the diffusion bonding boundary between the original copper interlayer and the diffusion zone in the SS side, and The J/I interface is the boundary of different diffusion belt in the original copper interlayer.

The fracture morphologies of the diffusion bonding joint for $\mathrm{Be} / \mathrm{Cu} / 00 \mathrm{Cr} 17 \mathrm{Ni} 14 \mathrm{Mo} 2$ stainless steel show in Fig. 2, which intermetallic compounds grow up along the grain boundary and form finally a three-dimensional network structure, and there are microcracks or grooves in the grain boundaries, it is reason that the specimen are the brittle fracture on the grain boundary. The XRD patterns of stripping layer from the SS side fracture to the SS matrix and from the beryllium side fracture to the beryllium matrix are shown in Fig. 3 and in Fig. 4, respectively. The results of XRD phase analysis show that the fracture is brittle $\alpha$-Be (beryllium base solid solution) as matrix in the beryllium side, and the brittle $\mathrm{Be}_{2} \mathrm{Fe}$ and $\mathrm{Be}_{2} \mathrm{Cu}$ are distributed along the grain boundaries, while the fracture is brittle $\mathrm{BeCu}$ as matrix in the SS side, and the brittle $\mathrm{Be}_{2} \mathrm{Fe}$ and $\mathrm{Be}_{2} \mathrm{Cu}$ are distributed along the grain boundaries.

Table3.The EDS testing results of Fe, $\mathrm{Cr}, \mathrm{Ni}, \mathrm{Mo}$ and $\mathrm{Cu}$ in diffusing bonding zone, w/ \%

\begin{tabular}{ccccccccccccccccc}
\hline & $\mathrm{A}$ & $\mathrm{B}$ & $\mathrm{C}$ & $\mathrm{D}$ & $\mathrm{E}$ & $\mathrm{F}$ & $\mathrm{G}$ & $\mathrm{H}$ & $\mathrm{I}$ & $\mathrm{J}$ & $\mathrm{K}$ & $\mathrm{L}$ & $\mathrm{M}$ & $\mathrm{N}$ & $\mathrm{O}$ & $\mathrm{P}$ \\
\hline $\mathrm{Fe}$ & 66.7 & 58 & 72 & 69 & 66 & 62 & 3.5 & 2.8 & 2.5 & 3.7 & 3.1 & 2.6 & 1.6 & 1.4 & & \\
$\mathrm{Cr}$ & 18.2 & 14 & 18 & 20 & 18 & 19 & 0.6 & 0.5 & 0.2 & 0.3 & 0.2 & 0.1 & 0.2 & 0.1 & & \\
$\mathrm{Ni}$ & 13.2 & 25 & 7.6 & 2.3 & 2.1 & 2.1 & 9.5 & 9.3 & 8.6 & 4.6 & 2.7 & 0.7 & 0.7 & 0.8 & 0.6 & \\
$\mathrm{Mo}$ & 1.66 & 0.4 & 0.4 & 4.8 & 3.4 & 4.6 & 0.0 & 0.1 & 0.0 & 0.0 & 0.0 & 0.0 & 1.2 & 1.0 & 0.5 & 0.3 \\
$\mathrm{Cu}$ & 0.00 & 1.7 & 1.4 & 4.8 & 10 & 12 & 86 & 87 & 89 & 91 & 94 & 97 & 96 & 97 & 98 & 99 \\
\hline
\end{tabular}
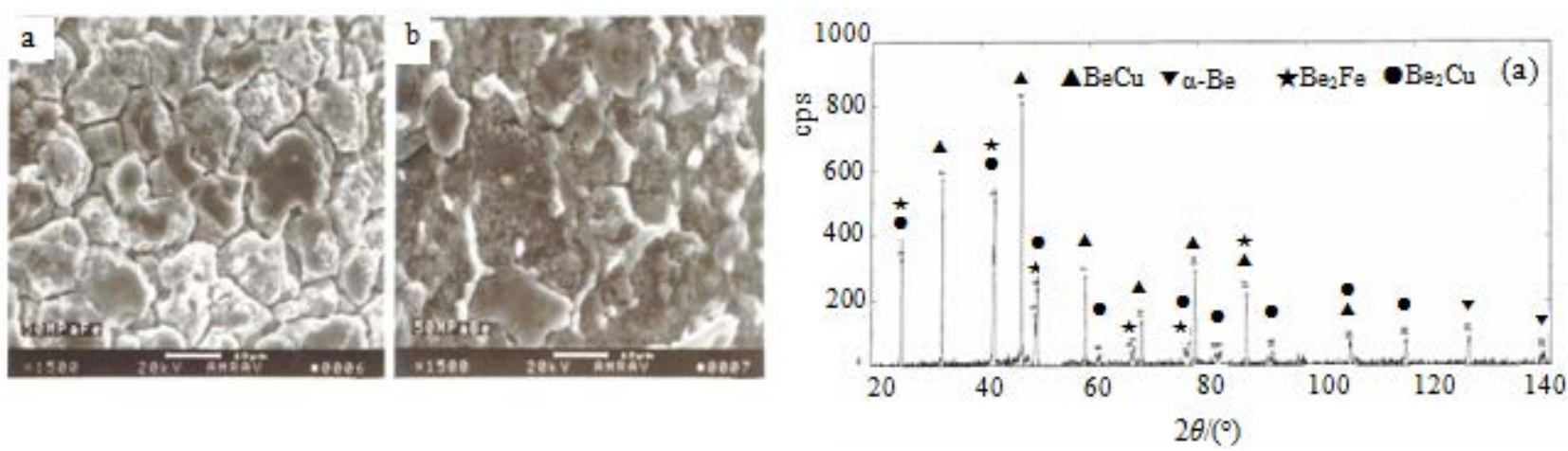

Fig.2 The fracture morphology of joint. (a) SS side, (b) Be side 

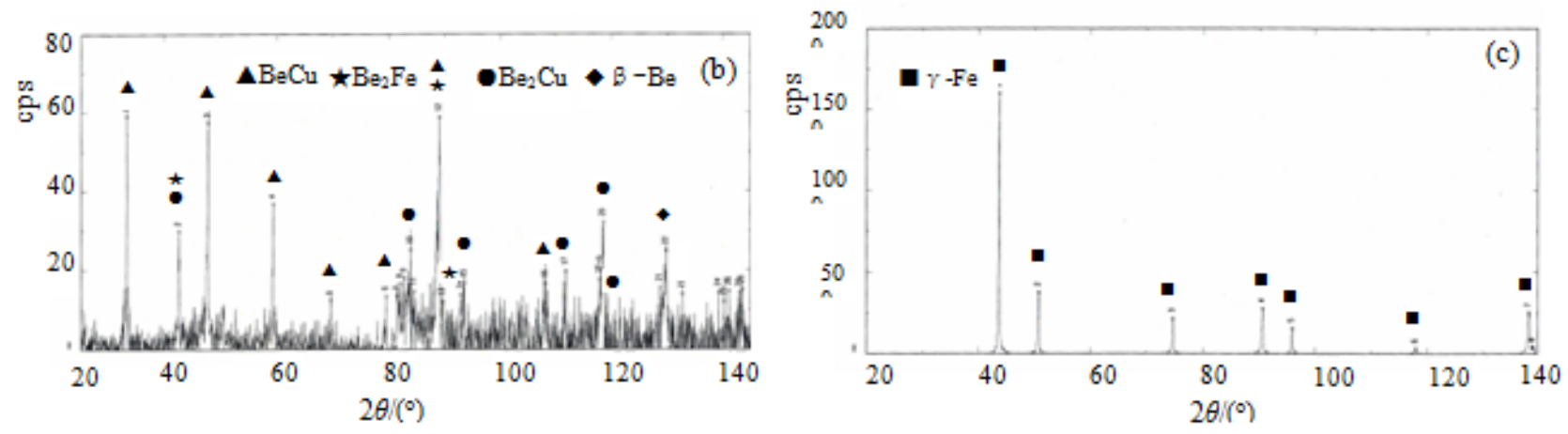

Fig. 3 The XRD patterns of the SS side fracture and after peeling layer.(a) SS side fracture, (b) after peeling $45 \mu \mathrm{m}$, (c) after peeling $60 \mu \mathrm{m}$
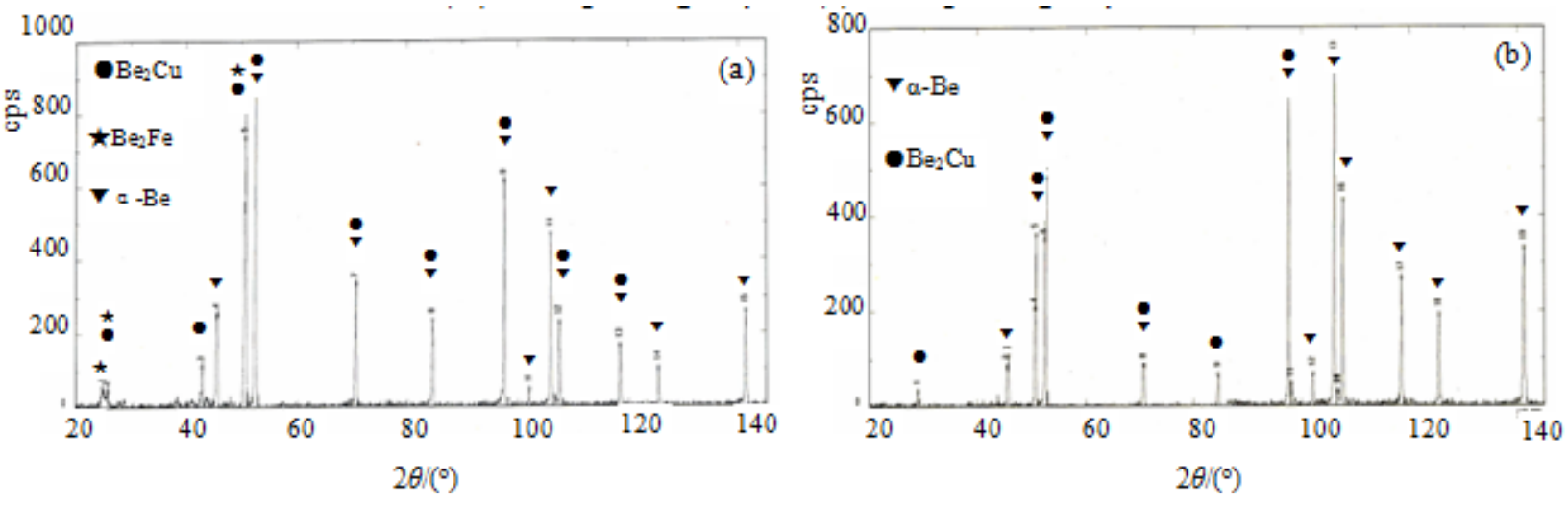

Fig. 4 The XRD patterns of the Be side fracture and after peeling layer.(a) Be side, ( b) after peeling $40 \mu \mathrm{m}$

In $\mathrm{Be} / \mathrm{Cu} / 00 \mathrm{Cr} 17 \mathrm{Ni14Mo} 2$ diffusion bonding process, first of all are the interdiffusion between $\mathrm{Be} \leftarrow \rightarrow \mathrm{Cu}$ and $\mathrm{Fe} \leftarrow \rightarrow \mathrm{Cu}$, then lead to the interdiffusion between Be and $\mathrm{Fe}$. The $\mathrm{Cu}$-Fe binary phase diagram[9] shows that $\mathrm{Cu}$ and Fe can not form intermetallic compounds, and can only form small amount of solid solution with very low solid solubility under the condition of temperature $800^{\circ} \mathrm{C}$. Due to the concentration gradients of $\mathrm{Fe}$ and $\mathrm{Cu}$ are very large on the $\mathrm{Cu} / \mathrm{SS}$ interface, which promote the transfer of $\mathrm{Cu}$ to the SS and Fe to the copper interlayer, and Fe further spread to the beryllium side and result in forming $\mathrm{Be}_{2} \mathrm{Fe}$. Fig. 3 show that the diffraction intensities of $\mathrm{Be}_{2} \mathrm{Fe}$, $\mathrm{Be}_{2} \mathrm{Cu}$ and $\mathrm{BeCu}$ are decreased with the increase of the distance from the SS side fracture, which the lowest is at $45 \mu \mathrm{m}$ peeled from the SS side fracture and the background of spectral line is enhanced. Based on XRD principle, the phases diffraction intensity will decrease and the background intensity will increase when crystal lattice is distorted. Therefore, with temperature decrease after hot pressing, $\mathrm{Fe}$ and $\mathrm{Cu}$ are precipitated from the over saturated solid solution and lead to serious lattice distortion[10]. Fig. 3 c shows that the main phase is $\gamma$-Fe at $60 \mu \mathrm{m}$ peeled from the SS side fracture, which explains that serious lattice distortion area is at the bonding zone of copper and SS. The Be-Cu binary phase diagram[9] shows that the solid solubility of copper in $\alpha$-Be matrix and the solid solubility of beryllium in copper matrix are about $6 \%$ and $12 \%$ under the condition of temperature $800^{\circ} \mathrm{C}$, respectively, and $\mathrm{Be}_{2} \mathrm{Cu}$ and $\mathrm{BeCu}$ are formed in turn with copper content increasing. Therefore, we can infer that $\mathrm{Be}_{2} \mathrm{Cu}$ and $\mathrm{BeCu}$ formed in the copper side of the $\mathrm{Be} / \mathrm{Cu}$ interface, and $\mathrm{BeCu}$ is the matrix. The beryllium based solid solution with copper is formed first, then its over saturated copper with beryllium form $\mathrm{Be}_{2} \mathrm{Cu}$ in the beryllium side of the $\mathrm{Be} / \mathrm{Cu}$ interface, and it is difficult to form $\mathrm{BeCu}$. These inferences are consistent with the XRD analysis results in Fig. 3 and Fig. 4. Because the beryllium solid solubility is about $12 \%$ in copper matrix, the mutual diffusion ability between copper and beryllium is good and lead to form $\mathrm{Be}_{2} \mathrm{Fe}$ in the SS side. On the other hand, the formation of $\mathrm{Be}_{2} \mathrm{Cu}$ and $\mathrm{BeCu}$ improve diffusion ability of copper to beryllium matrix and beryllium to copper interlayer[11], and it is more easily to beryllium diffuse 
into the SS side and form $\mathrm{Be}_{2} \mathrm{Fe}$ in the SS side. With the decrease of temperature after hot pressing, the over saturation beryllium and copper are precipitated from the copper based solid solution and the beryllium based solid solution, respectively, and lead to lattice distortion in the original copper interlay region and the beryllium side. Due to solubility of copper in beryllium matrix is lower than one of beryllium in copper matrix, the lattice distortion degree in the beryllium side is more serious than one in the original copper interlay region. Fig. 5 show the distributions of $\mathrm{Fe}, \mathrm{Be}, \mathrm{Cu}, \mathrm{Cr}$ and $\mathrm{Ni}$ near the $\mathrm{Be} / \mathrm{Cu} / \mathrm{SS}$ bonding interface measured using $\mathrm{AES}$, which copper interlayer greatly hindered the $\mathrm{Fe}, \mathrm{Cr}$ and $\mathrm{Ni}$ into the beryllium side, thus prevent $\mathrm{Be}_{21} \mathrm{Ni}_{5}, \mathrm{Be}_{12} \mathrm{Cr}$ and $\mathrm{NiBe}$ etc.forming in beryllium matrix, so the formation of intermetallic compounds between beryllium and stainless steel element are avoided effectively to improve the diffusion welding performance.

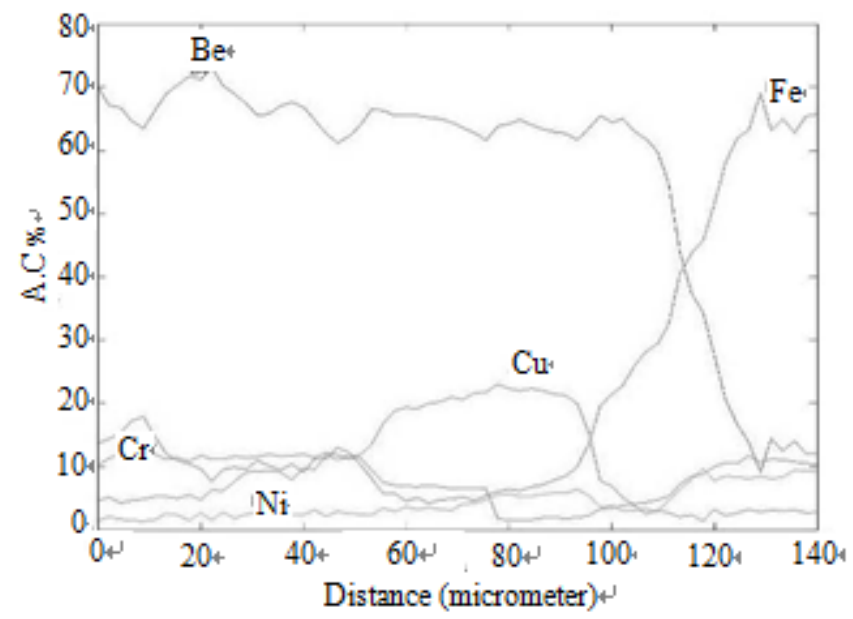

Fig.5 The element distribution at the interface of $\mathrm{Bc} / \mathrm{Cu} / \mathrm{SS}$ diffusion bonding

Therefore, both the original copper interlayer and the interface region of SS side are $\mathrm{BeCu}$ as matrix and $\mathrm{Be}_{2} \mathrm{Cu}, \mathrm{Be}_{2} \mathrm{Fe}$ distribute on BeCu grain boundary, so their structures are basically the same. It is reason that the bonding ability of the interface between the original copper interlayer and the SS side (Cu/SS interface) is good and the interface is combined closely. The interface region of beryllium side is $\alpha$-Be (beryllium base solid solution) as matrix and $\mathrm{Be}_{2} \mathrm{Cu}, \mathrm{Be}_{2} \mathrm{Fe}$ distribute on $\alpha$-Be grain boundary, which make a great difference with the structure of the original copper interlayer. The lattice static distortion and the forming phases between the original copper interlayer and the interface region of the beryllium side are very different, which causing different volume change produces large internal stress field. It is reason that the interface between the original copper interlayer and the beryllium side $(\mathrm{Cu} / \mathrm{Be}$ interface) is the most weak site of the whole diffusion bonding zone and the fracture site of specimen.

The test results of tensile strength show that the tensile strength of Be/00Cr17Ni14Mo2 stainless steel was $12 \mathrm{MPa}$, while the tensile strength of $\mathrm{Be} / \mathrm{Cu} / 00 \mathrm{Cr} 17 \mathrm{Ni} 14 \mathrm{Mo} 2$ stainless steel was $60 \mathrm{MPa}$.

\section{Conclusion}

1) During Be/Cu/00Cr17Ni14Mo2 stainless steel diffusion bonding, dissimilar metal atoms first gather and form intermetallic compounds on the grain boundaries, which causing stress concentration and the microcrack are the main reason why reduce the diffusion bonding performance.

2) During $\mathrm{Be} / \mathrm{Cu} / 00 \mathrm{Cr} 17 \mathrm{Ni14Mo2}$ stainless steel diffusion bonding, the crystal structure exist in a great difference on the both sides of the $\mathrm{Be} / \mathrm{Cu}$ interface, and there is large internal stress on the $\mathrm{Be} / \mathrm{Cu}$ interface zone, so the $\mathrm{Be} / \mathrm{Cu}$ interface is the most weak site of the whole diffusion bonding zone and fracture site of specimen. 
3) The copper interlayer has greatly hindered the diffusion of Fe and other alloy elements to the beryllium side, and reduced the formation of intermetallic compounds and improved the joint performance.

\section{References}

[1] Basuki Widodo Widjaja, Aktaa Jarir, Process optimization for diffusion bonding of tungsten with EUROFER97 using a vanadium interlayer, J. Journal of Nuclear Materials.459 (2015) 217-224.

[2] Halbig M.C., Asthana R., Singh M., Diffusion bonding of SiC fiber-bonded ceramics using Ti/Mo and Ti/Cu interlayers, J. Ceramics International. 41 (2015) 2140-2149.

[3] Cai Qingshan, Liu Wensheng, Ma Yunzhu, Liu Haoyang, Microstructure, residual stresses and mechanical properties of diffusion bonded tungsten-steel joint using a $\mathrm{V} / \mathrm{Cu}$ composite barrier interlayer, J. International Journal of Refractory Metals and Hard Materials. 48 ( 2015) 312-317.

[4] Balasubramanian M., Characterization of diffusion-bonded titanium alloy and 304 stainless steel with Ag as an interlayer, J. International Journal of Advanced Manufacturing Technology. 7 (2015) 3833-3838.

[5] He Peng, Wang Jun, Lin Tiesong, Li Haixin, Effect of hydrogen on diffusion bonding of TiAlbased intermetallics and Ni-based superalloy using hydrogenated Ti6Al4V interlayer, J. International Journal of Hydrogen Energy. 39 (2014) 1882-1887.

[6] Kim Jung Su, Lee Kwang Seok, Kwon Yong Nam, Lee Byeong Joo, Chang Young Won and Lee Sunghak, Improvement of interfacial bonding strength in roll-bonded $\mathrm{Mg} / \mathrm{Al}$ clad sheets through annealing and secondary rolling process, J. Materials Science and Engineering A, 68 (2015) $1-10$.

[7] Satoh Toshikazu and Ishizaki Toshitaka, Enhanced pressure-free bonding using mixture of $\mathrm{Cu}$ and NiO nanoparticles, J. Journal of Alloys and Compounds, 629 (2015) 118-123.

[8] Dejun Kong and Haoyuan Guo, Analysis of structure and bonding strength of AlTiN coatings by cathodic ion plating, J. Applied Physics A: Materials Science and Processing. 119 (2015) 309-316.

[9] Dai Yongnian, Binary Alloy Phase Diagrams, Science Press, Beijing 2009.

[10] Zhou Shangqi, X - ray diffraction analysis, Chongqing University Press, Chongqing 1991.

[11] Guoliang Cheng and Junpin Lin, Ordered intermetallic compounds based on materials physical metallurgy, Metallurgy Industry Press, Beijing 1999. 